This is the peer reviewed version of the following article: https://doi.org/10.1002/ejsp.2343, which has been published in final form at 10.1002/ejsp.2343https://doi.org/10.1002/ejsp.2343. This article may be used for noncommercial purposes in accordance with Wiley Terms

\title{
Gaming motivation and problematic video gaming: The role of needs frustration
}

\begin{abstract}
Motivation is often used as a predictor of a problematic style of video game engagement, implying that individuals' gaming undermines optimal functioning. Drawing from recent advances in Self-Determination Theory (SDT), the present study explores the links between gaming motivations, the daily frustration of basic psychological needs, and reports of problematic video gaming (PVG). A sample of 1029 participants $(72.8 \%$ male; $M=22.96$ years; $S D=4.13$ years) completed items regarding their gaming engagement and gaming motivation as well as their experience of needs frustration and PVG symptoms. Results revealed positive associations between gaming motivations and PVG, and between daily needs frustration and PVG. Finally, after comparing several competing models, a mediational model whereby needs frustration explained the association between individuals' gaming motivation and PVG emerged as best fitting the data. The discussion addresses the theoretical and practical implications of these findings in the context of recent research.
\end{abstract}

Self-Determination Theory (SDT; Ryan \& Deci, 2000, 2017) is a widely used theory of human motivation that emphasizes the quality versus the quantity of motivation in explaining consequences from activity engagement. SDT proposes more adaptive outcomes will occur when activity engagement is freely chosen and based solely on the pleasure and enjoyment of the activity itself (i.e., intrinsic motivation). Studies have shown less intrinsic motivation toward gambling- or exercise-related activities is associated with reports of greater gambling disorder and exercise dependence, respectively (Clarke, 2004; González-Cutre \& Sicilia, 2012). Intrinsic motivation is assumed to stem from greater satisfaction of three basic psychological needs 
This is the peer reviewed version of the following article: https://doi.org/10.1002/ejsp.2343, which has been published in final form at 10.1002/ejsp.2343https://doi.org/10.1002/ejsp.2343. This article may be used for noncommercial purposes in accordance with Wiley Terms

(competence, autonomy, and relatedness) during engagement in the activity, which implies that gambling disorder and exercise dependence are associated with lower needs satisfaction during engagement in related activities. However, active impediments to needs satisfaction, or needs frustration, within domains unrelated to the activity may ultimately cultivate a problematic pattern of activity engagement, as individuals become more reliant upon the activity to satisfy these needs (Vansteenkiste \& Ryan, 2013). To date, no study has explored the contributions of both activity motivation and the experience of needs frustration in predicting problematic activity engagement. Therefore, within the quickly growing area of video games, the present study explores the unique roles gaming motivation and experiences of needs frustration play in explaining problematic video gaming.

Self-Determination Theory (SDT; Ryan \& Deci, 2000, 2017) proposes three interrelated types of motivation underlying activity engagement that are easily applied to video games. An intrinsic motivation is guided by the pleasure and enjoyment from video games. An amotivation indicates that video games are perceived to add little value to life resulting in a lack of personal intention to engage in them. Between an intrinsic motivation and an amotivation there lie four subtypes of extrinsic motivation. The first, integrated regulation, is guided by the personal expression of self through video game engagement (Ryan \& Deci, 2017). The second, identified regulation, is characterized by the alignment of video game engagement with one's values and goals (Ryan, 1995). The third, introjected regulation, indicates experiencing strong internal pressures to engage in video games that are beyond the control of the individual (Ryan \& Deci, 2000). Finally, the fourth, external regulation, is driven by the desire to earn rewards through gaming (Ryan, 1995). In line with assumptions of SDT, the abovementioned motivations toward 
This is the peer reviewed version of the following article: https://doi.org/10.1002/ejsp.2343, which has been published in final form at 10.1002/ejsp.2343https://doi.org/10.1002/ejsp.2343. This article may be used for noncommercial purposes in accordance with Wiley Terms

gaming have been found to be positively associated with time spent gaming except for an amotivation toward gaming (Lafrenière, Verner-Filion, \& Vallerand, 2012).

Interwoven within SDT's perspective on motivation is the role of three basic psychological needs. The three needs include competence (i.e., perceiving one's abilities are well-matched with the activity), autonomy (i.e., perceiving actions while engaging in the activity are under one's own volition), and relatedness (i.e., perceiving a sense of connectedness with others through engagement in the activity) (Ryan \& Deci, 2000, 2017). Reporting greater satisfaction of these needs during activity engagement is expected to concomitantly occur with a stronger intrinsic motivation (Ryan, 1995). Consistent with this assumption, Lafrenière et al. (2012) observed that a stronger intrinsic motivation toward gaming was associated with perceiving higher needs satisfaction during gaming. Other research has demonstrated that higher game enjoyment, stronger intentions to play, and greater time spent gaming are further predicted by greater needs satisfaction during video game engagement (Johnson, Gardner, \& Sweetser, 2016; Ryan, Rigby, \& Przybylski, 2006; Tamborini, Bowman, Eden, Grizzard, \& Organ, 2010). Therefore, needs satisfaction while gaming appears to explain the appeal of video games (see review by Przybylski, Rigby, \& Ryan, 2010), but, as shown within a recent study, does not meaningfully explain problematic video gaming (PVG; Mills, Milyavskaya, Mettler, \& Heath, 2017).

PVG is a pattern of video game engagement that contributes to maladaptive functioning in daily life (King, Haagsma, Delfabbro, Gradisar, \& Griffiths, 2013; Petry et al., 2014). PVG is conceptually similar to other behavioral addictions such as gambling disorder and exercise dependence (Hausenblas \& Symons Downs, 2002), which have been found to be most strongly associated with an introjected regulation and amotivation. Demographically, PVG is more 
This is the peer reviewed version of the following article: https://doi.org/10.1002/ejsp.2343, which has been published in final form at 10.1002/ejsp.2343https://doi.org/10.1002/ejsp.2343. This article may be used for noncommercial purposes in accordance with Wiley Terms

commonly reported by males than females, and by those spending large amounts of time playing video games (Jeromin, Rief, \& Barke, 2016; Lemmens, Valkenburg, \& Gentile, 2015). Research has demonstrated that various measures of PVG are associated maladaptive outcomes including depression, impulsivity, conduct disorder, anxiety, and other psychological disorders (Bargeron \& Hormes, 2017; Strittmatter et al., 2015; Vadlin, Åslund, Hellström, \& Nilsson, 2016).

Although beyond the scope of this article to discuss in detail, it is important to note that a consensus has not been reached regarding the criteria of PVG or the weight that should be given to PVG as a potential disorder (Aarseth et al., 2016; Griffiths et al., 2016; Przybylski, Weinstein, \& Murayama, 2017). Nonetheless, PVG represents an area in which to build upon previous applications of SDT to the study of gaming.

Recent developments in SDT suggest that needs frustration, or the extent to which individuals feel obstructed in their pursuit of satisfying their needs in daily life (Vansteenkiste \& Ryan, 2013), may be a more robust predictor of behavioral addictions such as PVG. Studies show the active obstruction component that defines needs frustration is essential to predicting maladaptive outcomes (e.g., depression, interpersonal sensitivity), whereas low needs satisfaction that is void of any obstruction will weakly predict adaptive outcomes (e.g., life satisfaction, vitality) (Chen et al., 2015; Costa, Ntoumanis, \& Bartholomew, 2015; Gunnell, Crocker, Wilson, Mack, \& Zumbo, 2013). Previous research has also shown that needs frustration during participation in a mandatory (e.g., school) or loved activity (e.g., sport) is associated with less intrinsic motivation toward the activity as well as maladaptive outcomes (Costa, Coppolino, \& Oliva, 2016; Haerens, Aelterman, Vansteenkiste, Soenens, \& Van Petegem, 2015). However, in line with Vansteenkiste and Ryan (2013), needs frustration across 
This is the peer reviewed version of the following article: https://doi.org/10.1002/ejsp.2343, which has been published in final form at 10.1002/ejsp.2343https://doi.org/10.1002/ejsp.2343. This article may be used for noncommercial purposes in accordance with Wiley Terms

life domains may cultivate a dependence on one activity for needs satisfaction, alluding to a problematic style of engagement.

The present study has two objectives. The first objective sought to assess the associations among gaming motivations, daily needs frustration, and PVG. It was hypothesized that introjected regulation, external regulation, and amotivation would be positively correlated with competence, autonomy, and relatedness frustration. PVG was hypothesized to be positively associated with all six gaming motivations as well as reports of competence, autonomy, and relatedness frustration.

The second objective sought to assess how gaming motivations, daily needs frustration, and PVG were related. At present, theory and previous research offer at least three potential models explaining how these constructs are related. The first model (Model A in Figure 1) suggests gaming motivations and daily needs frustration are best viewed as separate predictors of PVG. This model is supported by the theoretical and empirical evidence reviewed above. Alternatively, gaming motivations may explain the link between needs frustration and PVG. The second model (Model B in Figure 1) draws upon recent results from Lalande and colleagues (2017) who provided evidence that deficits in needs satisfaction are associated with lower life satisfaction through a stronger extrinsic motivation toward a loved activity. The deficits in needs satisfaction, per Lalande and colleagues (2017), bring about an overreliance toward one activity to satisfy basic needs, which over time undermines the potential of an intrinsic motivation toward an activity. However, it is possible that experiences of needs frustration explain the link between gaming motivations and PVG. This final model (Model C in Figure 1) suggests gaming motivations contribute to reports of PVG through increased experiences of needs frustration. Although this model does not have as much empirical support as Model A or Model B, recent 
This is the peer reviewed version of the following article: https://doi.org/10.1002/ejsp.2343, which has been published in final form at 10.1002/ejsp.2343https://doi.org/10.1002/ejsp.2343. This article may be used for noncommercial purposes in accordance with Wiley Terms

research in a tangentially related area of study demonstrated that perfectionism contributes to the presence of eating disorders through an increase in daily needs frustration (Boone,

Vansteenkiste, Soenens, Van der Kaap-Deeder, \& Verstuyf, 2014). Conceptualizations of perfectionism do parallel some of the broad qualities of introjected regulation including an inability to control internal pressures. As such, perfectionist individuals demonstrate a unique interaction with their environment that may cultivate a greater susceptibility for experiencing needs frustration. Therefore, with regard to gaming motivation, Model C suggests that the internalization of a strong extrinsic motivation may also contribute to the experience of daily needs frustration because it represents how individuals might interact with their environment similar to reports of perfectionism.

Other models beyond the three outlined above were considered, but were not found to have justification in existing theory or available evidence resulting in their exclusion. Given the previously mentioned links to PVG, gender and time spent gaming were included as covariates.

\section{Methods}

\section{Participants}

Ethical approval from McGill University was given prior to recruitment, and all participants provided their informed consent before beginning the online questionnaire. In total, 1802 participants were recruited through online social networks (e.g., Facebook, Reddit) and research forums (e.g., Psychological Research on the Net), email invitations, and flyers. The dataset was reviewed for duplicate IP addresses in which the earliest response was retained with the latter responses excluded $(n=59)$. Further, participants less than 18 years $(n=43)$ or over 35 years $(n=61)$ were excluded, as this range corresponded with significant portion of video game 
This is the peer reviewed version of the following article: https://doi.org/10.1002/ejsp.2343, which has been published in final form at 10.1002/ejsp.2343https://doi.org/10.1002/ejsp.2343. This article may be used for noncommercial purposes in accordance with Wiley Terms

users (Entertainment Software Association, 2016). Additionally, 251 participants did not complete the online survey and were thus excluded. Finally, 359 participants were excluded for responding to an attention item incorrectly, or responding "No" to the question, "Do you play video games most days of the week", suggesting they are not frequent video game users. Comparisons of gender, age, and time spent gaming were conducted between those included and those excluded, which did not reveal any significant differences $(p>.05)$.

The final sample included 1029 participants $(72.8 \%$ male; $M=22.96$ years; $S D=4.13$ years). On average, participants spend 19.70 hours ( $S D=15.34$ hours) per week gaming. Participants were from the United States (46.4\%), Canada (33.1\%), as well as various European (12.2\%) and Asian (3.4\%) countries. Most participants (64\%) reported they were presently enrolled at a post-secondary institution.

\section{Measures}

\section{Problematic video gaming}

The 9-item Internet Gaming Disorder Scale (IDGS; Lemmens et al., 2015) was used to assess PVG. Participants rated the frequency they experienced each item over the last year using an altered 6-point scale ranging from almost never (1) to almost always (6). Internal consistency was acceptable $(\alpha=.85)$.

\section{Needs frustration}

Bartholomew, Ntoumanis, Ryan, and Thøgersen-Ntoumani's (2011) Psychological Need Thwarting Scale (PNTS) was adapted to assess needs frustration in daily life. The original scale consists of three 4-item subscales assessing the frustration of each psychological need. An item 
This is the peer reviewed version of the following article: https://doi.org/10.1002/ejsp.2343, which has been published in final form at 10.1002/ejsp.2343https://doi.org/10.1002/ejsp.2343. This article may be used for noncommercial purposes in accordance with Wiley Terms

from the relatedness subscale (REL2) was not included in the questionnaire due to a previous study finding it was confusing and ultimately did not load highly onto its respective factor (Mills et al., 2017). Participants used the same 6-point scale as the IDGS to rate how frequently they experience each item in their life. Internal consistency was acceptable for the competence $(\alpha=$ $.82)$, autonomy $(\alpha=.88)$, and relatedness $(\alpha=.89)$ frustration subscales.

\section{Gaming motivation scale}

Lafrenière et al. (2012) developed the 18-item Gaming Motivation Scale (GAMS) to assess users' motivation toward gaming. The scale includes 6 three-item subscales that assess intrinsic motivation, amotivation, and each of the four subtypes of extrinsic motivation toward gaming (i.e., integrated regulation, identified regulation, introjected regulation, external regulation). Each item was rated on a 7-point scale ranging from not agree at all (1) to very strongly agree (7). Internal consistencies were all above .70 for each subscale, except for the intrinsic motivation subscale $(\alpha=.60)$.

\section{Analytical Strategy}

Statistical analyses were conducted using MPlus version 7.4 with missing values estimated by full information maximum likelihood (Muthén \& Muthén, 2015). Bivariate correlations with a Bonferroni modified alpha $(p<.001)$ were conducted to assess the associations among gaming motivations, daily needs frustration, and PVG (Objective 1). Fit indices were calculated to assess the fit of the present data to each of the proposed models within Figure 1 (Objective 2). Goodness-of-fit was determined by values of .08 or lower for root mean square error of approximation (RMSEA), near or above .95 for both comparative fit index (CFI) and Tucker-Lewis Index (TLI), and less than .06 for standardized root mean squared residual 
This is the peer reviewed version of the following article: https://doi.org/10.1002/ejsp.2343, which has been published in final form at 10.1002/ejsp.2343https://doi.org/10.1002/ejsp.2343. This article may be used for noncommercial purposes in accordance with Wiley Terms

(SRMR) (Hu \& Bentler, 1999; Kline, 2016). Additionally, Akaike's information criterion (AIC) and Bayesian information criterion (BIC) were used to compare models with lower values suggesting greater parsimony (Kline, 2016; Wagenmakers, 2007). Prior to conducting these analyses, the underlying factor structure of each measure was confirmed with the present data. The input and output of the preliminary and primary analyses as well as the individual items for each of the measures are provided as online supplemental material.

\section{Results}

\section{Preliminary Analyses}

A complete description of the steps taken to confirm each of the measures is provided in the online supplemental material. Although only minor modifications were made to IGDS to confirm a single factor solution, both the PNTS and the GAMS required further steps. First, an item from the competence subscale of the PNTS was excluded due to loading poorly onto its respective factor. Following its removal, the present data were found to fit the expected 3-factor solution. The revised 3-item competence subscale was found to have adequate internal consistency $(\alpha=.89)$. Second, following several steps that resulted in not confirming the 6 -factor solution for the GAMS, the entire intrinsic motivation subscale was excluded. Several steps were taken including an exploratory factor analysis with Promax rotation as well as confirmatory factor analysis with the remaining 15 items. In the end, four unique factors were identified with adequate internal consistency: Integrated-Identified Regulation $(\alpha=.88)$, Introjected Regulation $(\alpha=.74)$, External Regulation $(\alpha=.70)$, and Amotivation $(\alpha=.87)$. The interested reader is encouraged to review the online supplemental material for further explanation of these steps. Not surprisingly, participants recruited from gaming-specific Reddit streams reported greater time 
This is the peer reviewed version of the following article: https://doi.org/10.1002/ejsp.2343, which has been published in final form at 10.1002/ejsp.2343https://doi.org/10.1002/ejsp.2343. This article may be used for noncommercial purposes in accordance with Wiley Terms

spent gaming, stronger motivations toward gaming, and higher PVG than participants recruited using other methods $(p<.05)$. Table 1 presents the means and standard deviations of the included instruments.

\section{Primary Analyses}

The first objective was to assess the associations among gaming motivations, daily needs frustration, and PVG. Bivariate correlations (see Table 1) largely supported expected associations. Specifically, PVG was positively associated with each of the four gaming motivations as well as competence, autonomy, and relatedness frustration. Furthermore, competence, autonomy, and relatedness frustration were positively associated with introjected regulation and amotivation; however, external regulation was not associated with needs frustration.

The second objective assessed how gaming motivations, daily needs frustration, and PVG were related. Average scores for the four gaming motivations, daily frustration of each basic need, and PVG were included as observed variables within the planned path analyses. Time gaming and gender were included as covariates; however, several paths were excluded given the non-significant associations observed in Table 1. First, the pathways from time gaming to competence, autonomy, and relatedness frustration were excluded from the proposed models. Second, the pathways from gender to PVG, introjected regulation, external regulation, and amotivation were excluded from the proposed models.

An acceptable fit was found for each model (see Table 2); however, Model C was found to have the lowest AIC, which suggested it is the preferred model (Kline, 2016). Moreover, using an equation the provided by Wagenmakers (2007), the differences in BIC revealed "strong" 
This is the peer reviewed version of the following article: https://doi.org/10.1002/ejsp.2343, which has been published in final form at 10.1002/ejsp.2343https://doi.org/10.1002/ejsp.2343. This article may be used for noncommercial purposes in accordance with Wiley Terms

evidence that Model C is a more parsimonious model compared to Model A and Model B. In fact, according to Wagenmakers' equation, Model C is 30.4 times more likely than Model A and 28.2 times more likely than Model B. As shown in Figure 2, the results of this model show all four gaming motivations are directly associated with PVG. In addition to these direct effects, positive indirect effects for introjected regulation and amotivation were found through autonomy frustration (Introjected Regulation: $\beta=.03, p=.01,95 \mathrm{CI}[.01, .05]$; Amotivation: $\beta=.02, p=$ $.01,95 \mathrm{CI}[.01, .04])$. All other effects are included in the online supplemental material.

\section{Discussion}

The present study investigated the roles of both gaming motivations and daily needs frustration in explaining PVG. As expected, gaming motivations and daily needs frustration are positively associated with PVG. These associations are consistent with work in other areas of study (Boone et al., 2014; Clarke, 2004; Costa et al., 2016; González-Cutre \& Sicilia, 2012; Symons Downs, Savage, \& DiNallo, 2013). However, in building upon previous research, the present findings are the first to show that the experience of daily autonomy frustration partially mediates the association between both introjected regulation of and amotivation toward gaming and PVG. The discussion focuses on these two specific motivations to help explain PVG.

Introjected regulation implies that the drive to engage in video games is facilitated by uncontrollable internal pressures, which resemble withdrawal-like symptoms such as anxiety or irritability when unable to play (Ryan, 1995). Per SDT, these pressures stem from a contingent self-worth that is strongly attached to the activity, indicating engagement in the activity is an attempt to prove oneself. A recent study demonstrated that although each of the four types of extrinsic motivation as well as amotivation were positively correlated with a strong attachment 
This is the peer reviewed version of the following article: https://doi.org/10.1002/ejsp.2343, which has been published in final form at 10.1002/ejsp.2343https://doi.org/10.1002/ejsp.2343. This article may be used for noncommercial purposes in accordance with Wiley Terms

of self-esteem to video game engagement, introjected regulation of gaming engagement correlated highly $(r>.70)$ with the pursuit of individual validation through gaming (Beard \& Wickham, 2016). As such, introjected regulated video game users are compelled to play video games problematically due to the role gaming has on their perception of self, implying a larger issue surrounding problematic gaming cognitions (see work by King \& Delfabbro, 2014, 2016).

On the other hand, amotivation represents a perception that gaming does not provide value to one's life, culminating in a lack of personal intention in gaming engagement (Ryan, 1995). Although further research is needed, helplessness within the present context likely refers to an awareness of the negative consequences of gaming engagement, but an inability to stop or manage gaming engagement. As such, the link between amotivation toward gaming and PVG parallels the link between feeling "addicted” to gaming and PVG (Männikkö, Billieux, Nordström, Koivisto, \& Kääriäinen, 2017; Rehbein, Kliem, Baier, Mößle, \& Petry, 2015). Further, the strong correlation between introjected regulation and amotivation suggests the helplessness in effectively managing gaming engagement may stem from strong internal pressures to engage in gaming, which are coming into conflict with a heightened awareness that gaming no longer adds value to other life domains and may even be undermining quality of life (Ryan \& Deci, 2017).

Importantly, both introjected regulation and amotivation predicted increased frustration of all three basic needs; however, current theory does not explicitly address how these motivations might facilitate greater needs frustration. Only two studies have shown a mediational role of needs frustration in explaining the presence of a problematic behavior, and both used 
This is the peer reviewed version of the following article: https://doi.org/10.1002/ejsp.2343, which has been published in final form at 10.1002/ejsp.2343https://doi.org/10.1002/ejsp.2343. This article may be used for noncommercial purposes in accordance with Wiley Terms

reports of perfectionism as a predictor of needs frustration within a sport-specific context (Costa et al., 2016) or in daily life (Boone et al., 2014). Results demonstrated that perfectionism contributed to a problematic behavior (e.g., binge eating, exercise dependence) through an increase in needs frustration. Although the strong uncontrolled internal pressures to engage in video games parallel some of the broad elements of perfectionism, the overlap with amotivation is less clear. It is possible that perfectionistic individuals feel "addicted" to behaving a specific way and helpless to change their behavior. This overlap between introjected regulation and amotivation with perfectionism does not explain how needs frustration is facilitated.

One possible way in which introjected regulation and amotivation facilitate greater daily needs frustration is through a strong disengagement in environments unrelated to gaming resulting in an active avoidance of such environments. PVG is strongly related to the perception that the online gaming community is the only place in which one is valued and appreciated (Liu \& Peng, 2009). Indeed, these perceptions speak to a key component embedded within the introjected regulation of gaming engagement as well as the control gaming has over amotivated individuals. Strong beliefs that one is only valued within a gaming community will result in disengagement as well as greater aggression in both gaming and non-gaming environments. This increased aggression may bring about an exclusionary response from non-gaming environments. Future research is needed to assess for a recursive association, whereby perceptions of being valued only online stem from experiences of needs frustration. An important implication of Liu and Peng's (2009) finding is that enthusiastic but otherwise healthy users likely feel valued and appreciated in other areas of their life beyond gaming (e.g., work, school, friendships), limiting the control gaming has on their life. As shown in another study using adolescents, it is likely this 
This is the peer reviewed version of the following article: https://doi.org/10.1002/ejsp.2343, which has been published in final form at 10.1002/ejsp.2343https://doi.org/10.1002/ejsp.2343. This article may be used for noncommercial purposes in accordance with Wiley Terms

stems from a lack of daily needs frustration experienced within a key domain ( $\mathrm{Yu}, \mathrm{Li}, \&$ Zhang, 2015).

An interesting finding within the present study was that only autonomy frustration mediated the links introjected regulation and amotivation toward gaming and PVG. Autonomy frustration is critical in facilitating the development of a contingent or fragile self-esteem (Deci \& Ryan, 1995). Caution should be taken in interpreting the present results as suggesting that competence and relatedness frustration do not contribute to PVG. Rather, competence and relatedness frustration were found to contribute to PVG through a decline in subjective wellbeing (Mills et al., 2017). As such, these findings highlight the unique role motivations toward gaming may play in undermining daily autonomy satisfaction, which contributes to a strong attachment of self-esteem onto gaming engagement resulting in greater PVG.

Finally, it should be noted that both integrated-identified regulation and external regulation predicted PVG, but were not associated with needs frustration. This suggests that enthusiastic but otherwise healthy video game users who perceive gaming (1) provides personal expression (i.e., integrated regulation) and (2) is in alignment with values and goals (i.e., identified regulation) are likely to report some symptoms of PVG (Charlton \& Danforth, 2007), which is similar to the conceptualization of a harmonious passion (Vallerand, 2010). On the other hand, external regulation, which relates to being motivated to collect various rewards (e.g., leveling up, in-game awards), is not surprisingly related to PVG, as these elements will often relate directly to a surface-level appeal of gaming. However, these characteristics by themselves will likely not facilitate a sustained PVG. 
This is the peer reviewed version of the following article: https://doi.org/10.1002/ejsp.2343, which has been published in final form at 10.1002/ejsp.2343https://doi.org/10.1002/ejsp.2343. This article may be used for noncommercial purposes in accordance with Wiley Terms

Several limitations should be noted. First, the use of self-report data assumes participants correctly interpreted each item and responded truthfully; however, careful steps were taken in reviewing the measures as well as participants' responses to each item to ensure accuracy and validity. Second, because the present data did not confirm the original six-factor structure of the GAMS, the present findings are based upon a slightly incomplete picture of gaming motivation from the perspective of SDT. Future research is needed to revalidate the scale and its ability to adequately measure all six gaming motivations. Finally, due to the cross-sectional design, the present study is not able to infer causality. However, the data-driven approach taken is a strength of the present study as it compared a set of theoretically derived models, which ultimately revealed strong evidence of the likely relation among gaming motivations, needs frustration, and PVG.

Notwithstanding these limitations, the present study offers original contributions to both the SDT and PVG literature. Specifically, introjected regulation and amotivation play a role in explaining PVG through in part their effect on the experience of needs frustration. Although speculative, it is possible that clinicians might see changes in individuals' gaming patterns by directly addressing their motivations toward gaming through motivational interviewing (Miller \& Rollnick, 2013). Further, a recent study has shown a small but significant reduction of the association between needs frustration and ill-being for those reporting higher dispositional mindfulness (Schultz, Ryan, Niemiec, Legate, \& Williams, 2015), a quality of consciousness that may be increased through targeted training during interventions (Brown \& Ryan, 2003; Carmody $\&$ Baer, 2008). As these are speculative suggestions, research is needed to provide evidence of their merits within a clinical study. Furthermore, research should explore whether the link between needs frustration and PVG depends on the type of video games one primarily plays. 
This is the peer reviewed version of the following article: https://doi.org/10.1002/ejsp.2343, which has been published in final form at 10.1002/ejsp.2343https://doi.org/10.1002/ejsp.2343. This article may be used for noncommercial purposes in accordance with Wiley Terms

\section{References}

Aarseth, E., Bean, A. M., Boonen, H., Colder Carras, M., Coulson, M., Das, D., ... Van Rooij, A. J. (2016). Scholars? Open debate paper on the World Health Organization ICD-11 Gaming Disorder proposal. Journal of Behavioral Addictions, 6(3), 1-4. https://doiorg.proxy3.library.mcgill.ca/10.1556/2006.5.2016.088

Bargeron, A. H., \& Hormes, J. M. (2017). Psychosocial correlates of Internet Gaming Disorder: Psychopathology, life satisfaction, and impulsivity. Computers in Human Behavior, 68, 388-394. https://doi-org.proxy3.library.mcgill.ca/10.1016/j.chb.2016.11.029

Bartholomew, K., Ntoumanis, N., Ryan, R., \& Thøgersen-Ntoumani, C. (2011). Psychological need thwarting in the sport context: Assessing the darker side of athletic experience. Journal of Sport \& Exercise Psychology, 33(1), 75- 102. http://eprints.bham.ac.uk/602/

Beard, C. L., \& Wickham, R. E. (2016). Gaming-contingent self-worth, gaming motivation, and 
This is the peer reviewed version of the following article: https://doi.org/10.1002/ejsp.2343, which has been published in final form at 10.1002/ejsp.2343https://doi.org/10.1002/ejsp.2343. This article may be used for noncommercial purposes in accordance with Wiley Terms

internet gaming disorder. Computers in Human Behavior, 61, 507- 515. https://doiorg.proxy3.library.mcgill.ca/10.1016/j.chb.2016.03.046

Boone, L., Vansteenkiste, M., Soenens, B., Van der Kaap-Deeder, J., \& Verstuyf, J. (2014). Selfcritical perfectionism and binge eating symptoms: A longitudinal test of the intervening role of psychological need frustration. Journal of Counseling Psychology, 61(3), 363373. https://doi-org.proxy3.library.mcgill.ca/10.1037/a0036418

Brown, K., \& Ryan, R. (2003). The benefits of being present: Mindfulness and its role in psychological well-being. Journal of Personality and Social Psychology, 84(4), 822- 848.

Carmody, J., \& Baer, R. A. (2008). Relationships between mindfulness practice and levels of mindfulness, medical and psychological symptoms and well-being in a mindfulnessbased stress reduction program. Journal of Behavioral Medicine, 31(1), 23- 33. https://doi-org.proxy3.library.mcgill.ca/10.1007/s10865-007-9130-7

Charlton, J., \& Danforth, I. (2007). Distinguishing addiction and high engagement in the context of online game playing. Computers in Human Behavior, 23, 1531- 1548. https://doiorg.proxy3.library.mcgill.ca/10.1016/j.chb.2005.07.002

Chen, B., Vansteenkiste, M., Beyers, W., Boone, L., Deci, E. L., Van der Kaap-Deeder, J., ... Verstuyf, J. (2015). Basic psychological need satisfaction, need frustration, and need strength across four cultures. Motivation and Emotion, 39(2), 216-236. https://doiorg.proxy3.library.mcgill.ca/10.1007/s11031-014-9450-1

Clarke, D. (2004). Impulsiveness, locus of control, motivation and problem gambling. Journal of 
This is the peer reviewed version of the following article: https://doi.org/10.1002/ejsp.2343, which has been published in final form at 10.1002/ejsp.2343https://doi.org/10.1002/ejsp.2343. This article may be used for noncommercial purposes in accordance with Wiley Terms

Gambling Studies, 20(4), 319-345.

https://doiorg.proxy3.library.mcgill.ca/10.1007/s10899-004-4578-7

Costa, S., Coppolino, P., \& Oliva, P. (2016). Exercise dependence and maladaptive

perfectionism: The mediating role of basic psychological needs. International Journal of Mental Health and Addiction, 14(3), 241- 256. https://doiorg.proxy3.library.mcgill.ca/10.1007/s11469-015-9586-6

Costa, S., Ntoumanis, N., \& Bartholomew, K. J. (2015). Predicting the brighter and darker sides of interpersonal relationships: Does psychological need thwarting matter? Motivation and Emotion, 39(1), 11-24. 10.1007/s11031-014-9427-0

Deci, E. L., \& Ryan, R. M. (1995). Human autonomy: The basis for true self-esteem. In M. H. Kernis (Ed.), Efficacy, agency, and self-esteem (pp. 31- 51). New York: Springer.

Entertainment Software Association (2016). 2016: Sales, demographic, and usage data: Essential facts about the computer and video game industry. http://essentialfacts.theesa.com/Essential-Facts-2016.pdf

González-Cutre, D., \& Sicilia, Á. (2012). Motivation and exercise dependence: A study based on Self-Determination Theory. Research Quarterly for Exercise and Sport, 83(2), 318- 329. https://doi-org.proxy3.library.mcgill.ca/10.5641/027013612800745194

Griffiths, M., van Rooij, A. J., Kardefelt-Winther, D., Starcevic, V., Király, O., Pallesen, S., ... 
This is the peer reviewed version of the following article: https://doi.org/10.1002/ejsp.2343, which has been published in final form at 10.1002/ejsp.2343https://doi.org/10.1002/ejsp.2343. This article may be used for noncommercial purposes in accordance with Wiley Terms

Demetrovics, Z. (2016). Working towards an international consensus on criteria for assessing internet gaming disorder: A critical commentary on Petry et al. (2014).

Addiction, 111(1), 167- 175. https://doi-org.proxy3.library.mcgill.ca/10.1111/add.13057

Gunnell, K. E., Crocker, P. R. E., Wilson, P. M., Mack, D. E., \& Zumbo, B. D. (2013).

Psychological need satisfaction and thwarting: A test of Basic Psychological Needs Theory in physical activity contexts. Psychology of Sport and Exercise, 14(5), 599- 607. https://doi-org.proxy3.library.mcgill.ca/10.1016/j.psychsport.2013.03.007

Haerens, L., Aelterman, N., Vansteenkiste, M., Soenens, B., \& Van Petegem, S. (2015). Do perceived autonomy-supportive and controlling teaching relate to physical education students' motivational experiences through unique pathways? Distinguishing between the bright and dark side of motivation. Psychology of Sport and Exercise, 16(P3), 26- 36. https://doi-org.proxy3.library.mcgill.ca/10.1016/j.psychsport.2014.08.013

Hausenblas, H. A., \& Symons Downs, D. (2002). Exercise dependence: A systematic review. Psychology of Sport and Exercise, 3(2), 89- 123. https://doiorg.proxy3.library.mcgill.ca/10.1016/S1469-0292(00)00015-7

Hu, L., \& Bentler, P. M. (1999). Cutoff criteria for fit indexes in covariance structure analysis:

Conventional criteria versus new alternatives. Structural Equation Modeling: A Multidisciplinary Journal, 6(1), 1-55. https://doiorg.proxy3.library.mcgill.ca/10.1080/10705519909540118

Jeromin, F., Rief, W., \& Barke, A. (2016). Validation of the Internet Gaming Disorder 
This is the peer reviewed version of the following article: https://doi.org/10.1002/ejsp.2343, which has been published in final form at 10.1002/ejsp.2343https://doi.org/10.1002/ejsp.2343. This article may be used for noncommercial purposes in accordance with Wiley Terms

Questionnaire in a sample of adult German-speaking internet gamers. Cyberpsychology, Behavior, and Social Networking, 19(7), 453-459. https://doiorg.proxy3.library.mcgill.ca/10.1089/cyber.2016.0168

Johnson, D., Gardner, J., \& Sweetser, P. (2016). Motivations for videogame play: Predictors of time spent playing. Computers in Human Behavior, 63, 805- 812. https://doiorg.proxy3.library.mcgill.ca/10.1016/j.chb.2016.06.028

King, D. L., \& Delfabbro, P. H. (2014). The cognitive psychology of Internet Gaming Disorder. Clinical Psychology Review, 34(4), 298- 308. https://doiorg.proxy3.library.mcgill.ca/10.1016/j.cpr.2014.03.006

King, D. L., \& Delfabbro, P. H. (2016). The cognitive psychopathology of internet gaming disorder in adolescence. Journal of Abnormal Child Psychology, 44(8), 1635- 1645. https://doi-org.proxy3.library.mcgill.ca/10.1007/s10802-016-0135-y

King, D. L., Haagsma, M. C., Delfabbro, P. H., Gradisar, M., \& Griffiths, M. D. (2013). Toward a consensus definition of pathological video-gaming: A systematic review of psychometric assessment tools. Clinical Psychology Review, 33(3), 331-342. https://doiorg.proxy3.library.mcgill.ca/10.1016/j.cpr.2013.01.002

Kline, R. B. (2016). Principles and practice of structural equation modeling ( 4 th ed.). New York, NY: The Guilford Press.

Lafrenière, M.-A. K., Verner-Filion, J., \& Vallerand, R. J. (2012). Development and validation 
This is the peer reviewed version of the following article: https://doi.org/10.1002/ejsp.2343, which has been published in final form at 10.1002/ejsp.2343https://doi.org/10.1002/ejsp.2343. This article may be used for noncommercial purposes in accordance with Wiley Terms

of the Gaming Motivation Scale (GAMS). Personality and Individual Differences, 53(7), $827-831$.

Lalande, D., Vallerand, R. J., Lafrenière, M. A. K., Verner-Filion, J., Laurent, F. A., Forest, J., \&

Paquet, Y. (2017). Obsessive Passion: A compensatory response to unsatisfied needs. Journal of Personality, 85(2), 163- 178. https://doiorg.proxy3.library.mcgill.ca/10.1111/jopy.12229

Lemmens, J. S., Valkenburg, P. M., \& Gentile, D. A. (2015). The Internet Gaming Disorder Scale. Psychological Assessment, 27(2), 567-582. https://doiorg.proxy3.library.mcgill.ca/10.1037/pas0000062

Liu, M., \& Peng, W. (2009). Cognitive and psychological predictors of the negative outcomes associated with playing MMOGs (massively multiplayer online games). Computers in Human Behavior, 25(6), 1306- 1311. https://doiorg.proxy3.library.mcgill.ca/10.1016/j.chb.2009.06.002

Männikkö, N., Billieux, J., Nordström, T., Koivisto, K., \& Kääriäinen, M. (2017). Problematic gaming behaviour in Finnish adolescents and young adults: Relation to game genres, gaming motives and self-awareness of problematic use. International Journal of Mental Health and Addiction, 15(2), 324- 338. https://doiorg.proxy3.library.mcgill.ca/10.1007/s11469-016-9726-7

Miller, W., \& Rollnick, S. (2013). Motivational interviewing: Helping people change ( 3rd ed.). New York, NY: The Guilford Press. 
This is the peer reviewed version of the following article: https://doi.org/10.1002/ejsp.2343, which has been published in final form at 10.1002/ejsp.2343https://doi.org/10.1002/ejsp.2343. This article may be used for noncommercial purposes in accordance with Wiley Terms

Mills, D. J., Milyavskaya, M., Mettler, J., \& Heath, N. L. (2017). Understanding the associations among needs frustration, problematic gaming and subjective well-being. Unpublished Manuscript.

Muthén, L. K., \& Muthén, B. O. (2015). Mplus User's Guide ( 7th ed.). Los Angeles, CA.

Petry, N. M., Rehbein, F., Gentile, D. A., Lemmens, J. S., Rumpf, H.-J., Mößle, T., ... O'Brien, C. P. (2014). An international consensus for assessing internet gaming disorder using the new DSM-5 approach. Addiction, 109(9), 1399- 1406. https://doiorg.proxy3.library.mcgill.ca/10.1111/add.12457

Przybylski, A. K., Rigby, C. S., \& Ryan, R. M. (2010). A motivational model of video game engagement. Review of General Psychology, 14(2), 154- 166. https://doiorg.proxy3.library.mcgill.ca/10.1037/a0019440

Przybylski, A. K., Weinstein, N., \& Murayama, K. (2017). Internet Gaming Disorder: Investigating the clinical relevance of a new phenomenon. American Journal of Psychiatry, 174(3), 230-236. https://doiorg.proxy3.library.mcgill.ca/10.1176/appi.ajp.2016.16020224

Rehbein, F., Kliem, S., Baier, D., Mößle, T., \& Petry, N. M. (2015). Prevalence of Internet Gaming Disorder in German adolescents: Diagnostic contribution of the nine DSM-5 criteria in a statewide representative sample. Addiction, 110(5), 842-851. https://doiorg.proxy3.library.mcgill.ca/10.1111/add.12849 
This is the peer reviewed version of the following article: https://doi.org/10.1002/ejsp.2343, which has been published in final form at 10.1002/ejsp.2343https://doi.org/10.1002/ejsp.2343. This article may be used for noncommercial purposes in accordance with Wiley Terms

Ryan, R. M. (1995). Psychological needs and the facilitation of integrative processes. Journal of Personality, 63(3), 397-427. https://doi-org.proxy3.library.mcgill.ca/10.1111/j.14676494.1995.tb00501.x

Ryan, R. M., \& Deci, E. L. (2000). Self-Determination Theory and the facilitation of intrinsic motivation, social development, and well-being. American Psychologist, 55(1), 68- 78. https://doi-org.proxy3.library.mcgill.ca/10.1037/0003-066X.55.1.68

Ryan, R. M., \& Deci, E. L. (2017). Self-Determination Theory: Basic psychological needs in motivation, development, and wellness. New York, NY: Guilford Press.

Ryan, R. M., Rigby, C. S., \& Przybylski, A. K. (2006). The motivational pull of video games: A Self-Determination Theory approach. Motivation and Emotion, 30(4), 344- 360. https://doi-org.proxy3.library.mcgill.ca/10.1007/s11031-006-9051-8

Schultz, P. P., Ryan, R. M., Niemiec, C. P., Legate, N., \& Williams, G. C. (2015). Mindfulness, work climate, and psychological need satisfaction in employee well-being. Mindfulness, 6(5), 971-985. https://doi-org.proxy3.library.mcgill.ca/10.1007/s12671-014-0338-7

Strittmatter, E., Kaess, M., Parzer, P., Fischer, G., Carli, V., Hoven, C. W., ... Wasserman, D. (2015). Pathological Internet use among adolescents: Comparing gamers and nongamers. Psychiatry Research, 228(1), 128-135. https://doiorg.proxy3.library.mcgill.ca/10.1016/j.psychres.2015.04.029

Symons Downs, D., Savage, J. S., \& DiNallo, J. M. (2013). Self-determined to exercise? 
This is the peer reviewed version of the following article: https://doi.org/10.1002/ejsp.2343, which has been published in final form at 10.1002/ejsp.2343https://doi.org/10.1002/ejsp.2343. This article may be used for noncommercial purposes in accordance with Wiley Terms

Leisure-time exercise behavior, exercise motivation, and exercise dependence in youth. Journal of Physical Activity \& Health, 10, 176- 184.

Tamborini, R., Bowman, N. D., Eden, A., Grizzard, M., \& Organ, A. (2010). Defining media enjoyment as the satisfaction of intrinsic needs. Journal of Communication, 60(4), 758777. https://doi-org.proxy3.library.mcgill.ca/10.1111/j.1460-2466.2010.01513.x

Vadlin, S., Åslund, C., Hellström, C., \& Nilsson, K. W. (2016). Associations between problematic gaming and psychiatric symptoms among adolescents in two samples. Addictive Behaviors, 61, 8- 15. https://doiorg.proxy3.library.mcgill.ca/10.1016/j.addbeh.2016.05.001

Vallerand, R. J. (2010). On passion for life activities. Advances in Experimental Social Psychology, 42, 97- 193. https://doi-org.proxy3.library.mcgill.ca/10.1016/S00652601(10)42003-1

Vansteenkiste, M., \& Ryan, R. M. (2013). On psychological growth and vulnerability: Basic psychological need satisfaction and need frustration as a unifying principle. Journal of Psychotherapy Integration, 23(3), 263-280. https://doiorg.proxy3.library.mcgill.ca/10.1037/a0032359

Wagenmakers, E.-J. (2007). A practical solution to the pervasive problems of $\mathrm{p}$ values.

Psychonomic Bulletin \& Review, 14(5), 779- 804. https://doiorg.proxy3.library.mcgill.ca/10.3758/BF03194105

Yu, C., Li, X., \& Zhang, W. (2015). Predicting adolescent problematic online game use from 
This is the peer reviewed version of the following article: https://doi.org/10.1002/ejsp.2343, which has been published in final form at 10.1002/ejsp.2343https://doi.org/10.1002/ejsp.2343. This article may be used for noncommercial purposes in accordance with Wiley Terms

teacher autonomy support, basic psychological needs satisfaction, and school

engagement: A 2-year longitudinal study. Cyberpsychology, Behavior, and Social

Networking, 18(4), 228-233. https://doi-

org.proxy3.library.mcgill.ca/10.1089/cyber.2014.0385

\section{Tables and Figures}

Figure 1. Proposed models depicting the associations among gaming motivations, needs frustration, and problematic gaming

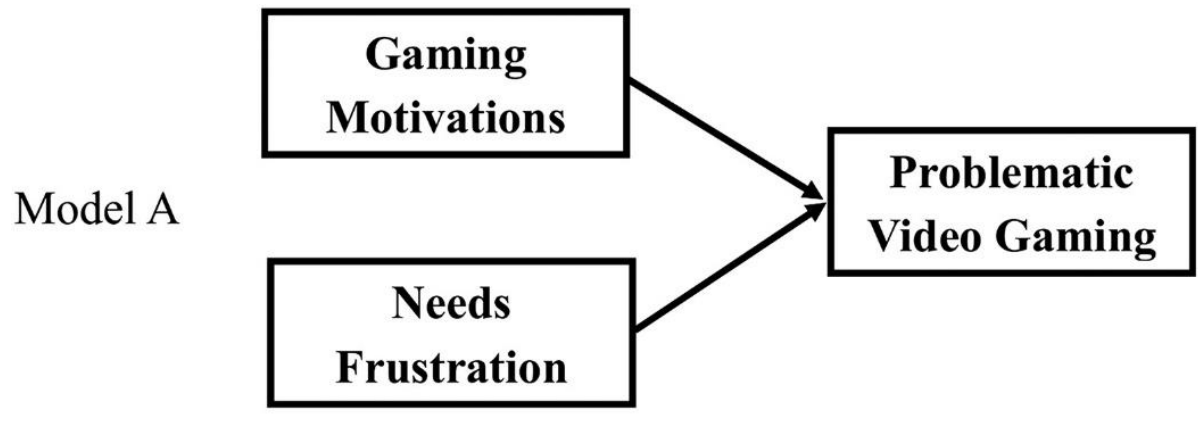

Model B

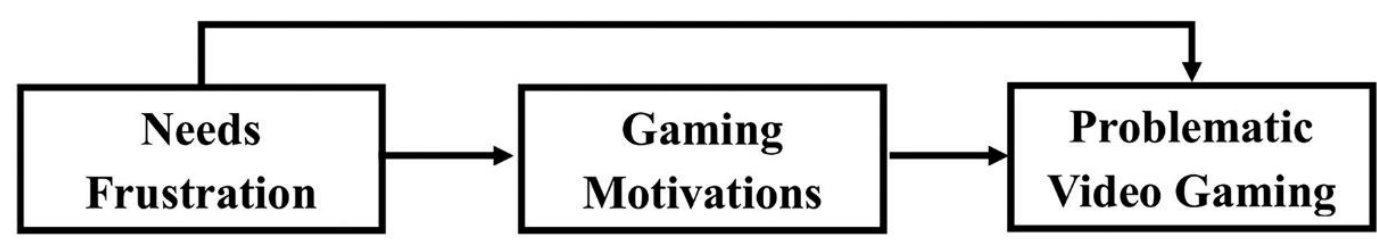

Model C

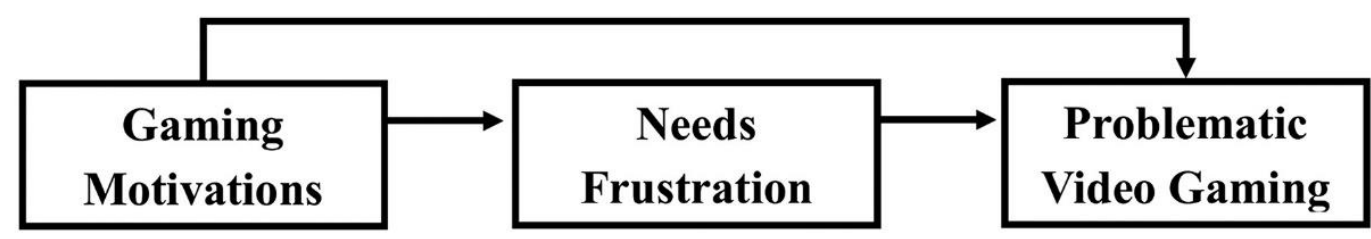


This is the peer reviewed version of the following article: https://doi.org/10.1002/ejsp.2343, which has been published in final form at 10.1002/ejsp.2343https://doi.org/10.1002/ejsp.2343. This article may be used for noncommercial purposes in accordance with Wiley Terms

Table 1. Correlation matrix presenting the associations among gender, hours spent gaming, problematic video gaming, gaming motivations, and needs frustration

Table 1. Correlation matrix presenting the associations among gender, hours spent gaming, problematic video gaming, gaming motivations, and needs frustration

\begin{tabular}{|c|c|c|c|c|c|c|c|c|c|c|}
\hline & 1 & $\begin{array}{l}2 \\
10\end{array}$ & 3 & 4 & 5 & 6 & 7 & 8 & 9 & \\
\hline 1. Gender $($ Males $=1 ;$ Females $=2)$ & - & & & & & & & & & \\
\hline 2. Hours Gaming & $-.26^{\star * \star}$ & - & & & & & & & & \\
\hline 3. Problematic Video Gaming & -.04 & $.24^{* * *}$ & - & & & & & & & \\
\hline 4. Integrated-Identified & $-.10^{* \star *}$ & $.36^{* * *}$ & $.38^{\star \star \star}$ & - & & & & & & \\
\hline 5. Introjected & -.02 & $.24^{* * *}$ & $.65^{\star \star \star}$ & $.47^{* \star *}$ & - & & & & & \\
\hline 6. External & -.07 & $.19^{* \star *}$ & $.36^{\star \star *}$ & .38 & $.42^{\star \star \star}$ & - & & & & \\
\hline 7. Amotivation & -.03 & $.12^{\star \star \star}$ & $.48^{\star \star \star}$ & $.04^{* \star *}$ & $.50^{\star \star \star}$ & .13 & - & & & \\
\hline 8. Competence Frustration & $.20^{\star \star \star}$ & .03 & $.36^{* * *}$ & $.12^{\star \star *}$ & $.35^{\star * *}$ & .09 & $.29^{\star \star \star}$ & - & & \\
\hline 9. Autonomy Frustration & $.15^{\star * *}$ & .04 & $.37^{* * *}$ & $.11^{* * *}$ & $.33^{* * *}$ & .10 & $.31^{* * *}$ & $.73^{* * *}$ & - & \\
\hline 10. Relatedness Frustration & $.20^{\star * \star}$ & .01 & $.28^{\star * \star}$ & .08 & $.28^{\star \star *}$ & .03 & $.27^{\star \star \star}$ & $.76^{\star * \star}$ & $.67^{\star \star *}$ & - \\
\hline Mean & - & 19.71 & 2.19 & 3.15 & 1.93 & 3.52 & 1.94 & 2.71 & 2.63 & 2.48 \\
\hline Standard Deviation & - & 15.33 & 0.84 & 1.44 & 1.14 & 1.51 & 1.33 & 1.28 & 1.62 & 1.32 \\
\hline
\end{tabular}

${ }^{* * *} p<.001$ (Bonferroni adjusted alpha).

Table 2. Fit statistics for the proposed models presented in Figure 1 explaining the roles of gaming motivations and the frustration of basic needs in explaining problematic video gaming

Table 2. Fit statistics for the proposed models presented in Figure 1 explaining the roles of gaming motivations and the frustration of basic needs in explaining problematic video gaming

\begin{tabular}{lccccccrr}
\hline & $\mathrm{X}^{2}$ & $d f$ & CFI & TLI & SRMR & RMSEA [90CI] & AIC & BIC \\
\hline Model A & 42.51 & 11 & .99 & .96 & .04 & $.05[.04, .07]$ & 32569.42 & 32835.98 \\
Model B & 40.13 & 11 & .99 & .96 & .04 & $.05[.03, .07]$ & 32567.79 & 32834.35 \\
Model Ca,b & 20.72 & 11 & 1.00 & .99 & .01 & $.03[.01, .05]$ & 32547.07 & 32813.63 \\
\hline
\end{tabular}

andicatesthe lowest AIC of all the models.

bIndicatesthe lowestBIC of all the models.

Figure 2. Path estimates for Model C. Correlations among the four gaming motivations as well as the frustration of each basic psychological need were not included for simplicity. Dash lines represent nonsignificant estimates. Significant estimates are indicated by a solid line and an $\left({ }^{*}\right)$. Confidence intervals $(95 \%)$ are provided in parentheses. ${ }^{*} \mathrm{p}<.05$; $^{* *} \mathrm{p}<.01{ }^{* * *} \mathrm{p}<.001$ 
This is the peer reviewed version of the following article: https://doi.org/10.1002/ejsp.2343, which has been published in final form at 10.1002/ejsp.2343https://doi.org/10.1002/ejsp.2343. This article may be used for noncommercial purposes in accordance with Wiley Terms

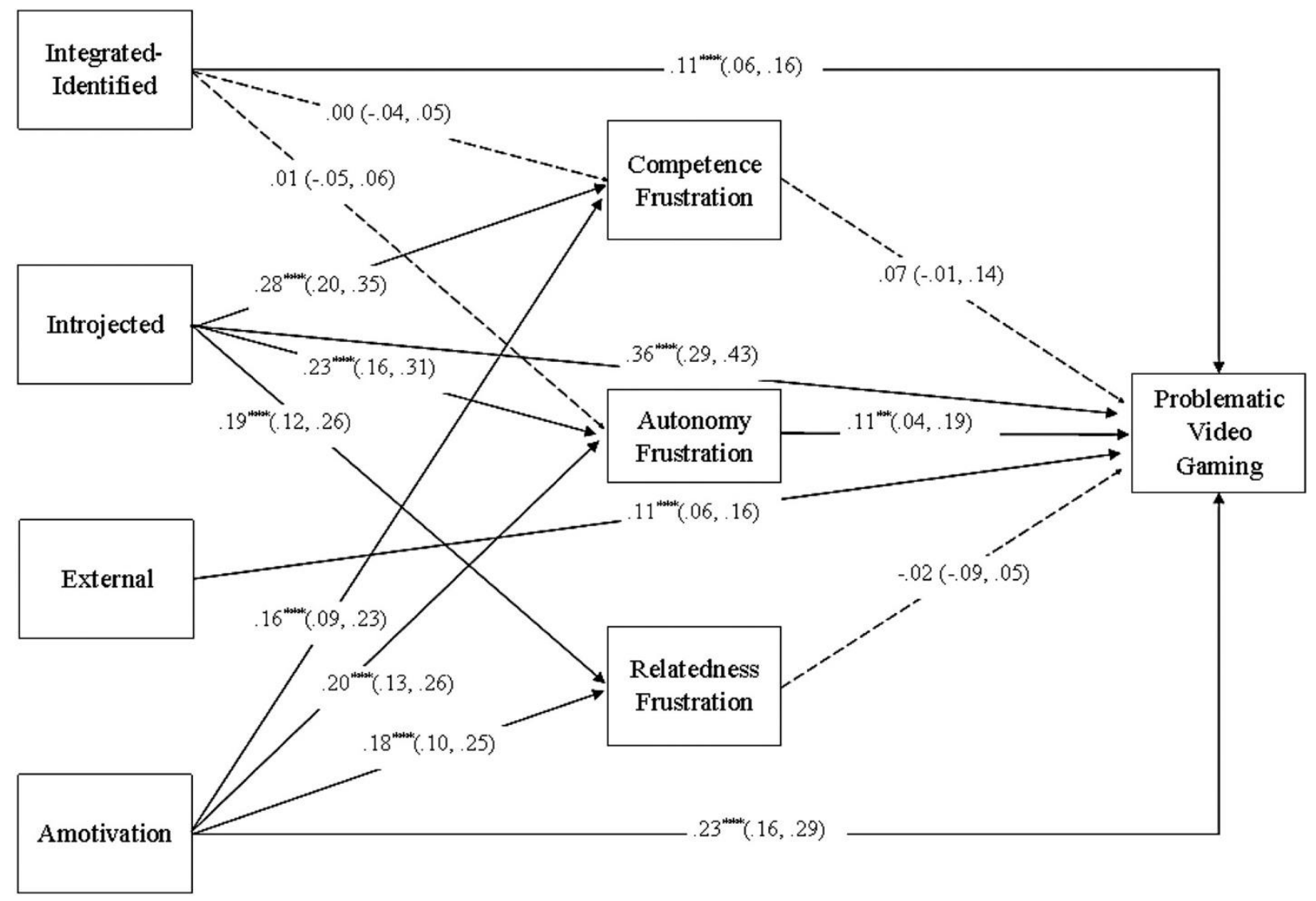

